The present books furnish abundant proof that this statement is particularly applicable to the Zeiss instruments in regard to the quality of those materials most essential for the production of good optical apparatus, viz. brains and knowledge of advanced mathematics.

G. H. Bryan.

\section{AMERICAN CYTOLOGY.}

Fecundation in Plants. By David M. Mottier, Ph.D. Pp. viii + I87. (Washington: Published by the Carnegie Institution, 1904.)

Contributions to the Knowledge of the Life-History of Pinus, with Special Reference to Sporogenesis, the Development of the Gametophytes and Fertilisation. By Margaret C. Ferguson, Ph. D. Pp. I53. (Washington: Published by the Washington Academy of Sciences, I904.)

W R. MOTTIER'S "Fecundation in Plants " gives $\mathrm{V}$ to those who are interested in cytology an account of the phenomena of fertilisation throughout the vegetable kingdom, written by one who has carried on investigations in several branches of the subject with success. His practical acquaintance with his subject confers even on his descriptions of the investigations of others a freshness which makes his work a pleasure to read. The first chapter is perhaps the most generally interesting. In it he gives an account of some of the vexed problems of karyology which are at present calling out so much controversy among cytologists. Among these problems may be mentioned the existence of centrosomes, the homology of centrosomes and blepharoplasts, the nature of synapsis, the significance of the sexual process, and the numerical reduction of chromosomes. The author's method of discussion is candid. He avoids being dogmatic in expressing his own views, although he criticises somewhat severely the observations of others. He holds that centrosomes and centrospheres do not occur in plants higher than the liverworts, and are, indeed, only well established in a few of the Thallophyta. It is remarkable that he does not allude to the possibility that the radiations at the poles of mitoses may be in part artefacts produced by the fixing agents. He considers Belajeff hasty in coming to the conclusion that the centrosome is the homologue of the blepharoplast; but he admits later on that certain "facts lend encouragement to the belief that centrosome and blepharoplast may be homologous structures." Mottier regards synapsis as due in a large measure to the action of reagents. He accepts Strasburger's theory of the numerical reduction of chromosomes as a good working hypothesis, and he holds now that there is no evidence for Weismann's "reduction" to be found in the mitoses of plants. His candid expression of doubt as to the persistent individuality of the chromosomes preserved through the successive mitoses-so often assumed, though almost involving a miraculous resurrection-is typical of his attitude of independence.

The succeeding chapters give an account of fertilisation in types taken from the various subdivisions of the vegetable kingdom. These descriptions are most useful in bringing together what is scattered NO. I 8.36 , vOL. $7 \mathrm{I}]$ sporadically through botanical literature into the compass of a short, well written book. The work is illustrated by blocks in the text, which show in a satisfactory manner the points to be brought out.

Miss Ferguson's memoir has a more limited scope, but this allows her to devote more space to her own researches, which have been very extensive in the cytology of the spore-production of conifers. It is quite remarkable to see how two cytologists, writing almost simultaneously, can hold so divergent views on fundamental subjects. While Mottier sees in the fusion of sexual nuclei the blending of two lines of descent, Miss Ferguson's researches lead her to believe that no fusion-nucleus, combining the paternal and maternal hereditary substances, is formed. Rather the processes of mitosis allow these to be kept apart during the life of the offspring, and the "reduction" or qualitative division occurring some time during the life-cycle secures that the gametes shall be "pure." It is evident that the later writer is concerned with the relation of mitosis to Mendel's views rather than to Weismann's hypothesis. With regard to synapsis, Miss Ferguson believes it to be a normal stage in heterotypic mitosis. Another point of difference is the mode of origin of the double chromosomes of heterotypic mitosis. Miss Ferguson finds confirmation in her preparations for the view (first published by the writer of this review in 1896 , Proc. Roy. Irish Acad.) that the two arms of the chromosomes are approximated pieces of the nuclear thread, and do not arise by longitudinal cleavage as Mottier believes. This interpretation seems to be gaining ground, and the Louvain school, once so much opposed to it, has recently accepted it, putting the folding back, however, to the synaptic stage. The reviewer's investigations seem to suggest the possibility that two distinct foldings take place, one during synapsis and another between that stage and the differentiation of the chromosomes. Whatever views are held on these disputed matters, all cytologists are indebted to the author for her beautiful drawings, which are reproduced in a series of twenty-four plates.

There is no doubt that the publication of these two memoirs, the one by the Carnegie Institution and the other by the Washington Academy, will be of much service to those engaged in cytological research.

H. H. D.

\section{PHYSICAL RESEARCH AT LEYDEN.}

Het Natuurkundig Laboratorium der Ryks-Universiteit te Leiden in de Jaren 1882-1904. Gedenkboek aangeboden aan den Hoogleeraar H. Kamerlingh Onnes, Directeur van het Laboratorium, by gelegenheid van zyn 25-jarig Doctoraat op Io Juli I904. Pp. viii +288 . (Leyden: Eduard Ydo, 1904.)

THIS volume was prepared by colleagues and pupils

of Prof. Kamerlingh Onnes, of Leyden University, and presented to him on the twenty-fifth anniversary of his receiving the degree of $\mathrm{Ph}$. D. It differs in character from the usual collections of scientific papers which it has become the fashion on the Continent to present to eminent men of science on 